\title{
Ground support and strata monitoring: what is needed?
}

\author{
O Vallati Sandvik Mining and Rock Technology, Australia \\ W Roach Sandvik Mining and Rock Technology, Australia \\ S Weaver Sandvik Mining and Rock Technology, Australia
}

\begin{abstract}
With the ever-moving challenge to increase safety and productivity in mines, the ability to understand what your strata is doing in 'real-time' is incredibly important. New technologies need to be developed to allow time efficient monitoring of strata behaviour over the excavations desired life, along with the condition of ground support systems and how effectively they are functioning.

Monitoring systems play an important function in maintaining the safe operation of underground mines. This paper will review technologies currently available; those being utilised and the effectiveness of such systems.

Key desired outputs will be investigated along with the constraints of available technologies. To assist the underground mining industry to continue evolving in this area, an overview of digital trends will be provided as a guide to the direction for current and future technology developments.
\end{abstract}

Keywords: monitoring, ground support, rockbolt, digitalisation, strata control, automation

\section{Introduction}

Strata support in an underground excavation is a primary concern for miners. Geotechnical engineers choose the optimal ground support scheme based on the rock mass properties, design guidelines and their experiences. Ground support elements are installed to stabilise the excavation and are divided in two groups: reinforcement and surface support. The first group includes components installed inside the rock mass. Rockbolts and cable bolts belong to this category. Rockbolts aim to stabilise the area near the excavation face for a depth of 2-3 m while cable bolts are used for support at greater depth (3-15 m) (Potvin \& Hadjigeorgiou 2020). Recent research is pushing towards products that are energy-absorbent for rockburst prone and squeezing ground conditions and allow for safe and rapid tunnelling operation such as the D47 MDX and the D39 MDX bolts (Roach et al. 2019). Reinforcements are used to stabilise and preserve the structural integrity of the rock mass, whereas surface support is in place on the face of the excavation to catch smaller loose rocks. Some examples of surface support include steel mesh, straps and shotcrete. In recent years, efforts have been dedicated to understanding the effectiveness of surface supports (Kanda \& Stacey 2019) and the interaction between reinforcement and surface supports in the case of dynamic loading (Morissette \& Hadjigeorgiou 2017).

Ground support elements should ensure a safe environment; therefore their performance and the rock mass behaviour should be monitored over time. Ground support elements are bound together with the rock mass and are directly influenced by movement of the strata. Consequently, it is essential to monitor the ground support, strata conditions and the interaction between them.

This paper, in line with similar works (Song et al. 2017; Bačić et al. 2019; Dawn 2019), aims to give an overview of modern technology for ground support and strata monitoring, with particular emphasis on new technological trends and digital transformation that is reaching the mining industry. 


\section{$2 \quad$ Ground support monitoring}

Understanding the performance of ground support in situ is essential. During their operational life, the ground support elements (reinforcement and surface support) may be subjected to extreme loading and environmental conditions, and consequently, degradation is inevitable. When damage of any element is over its functional limit, the system loses its support capability, leaving the excavation inadequately supported. Rockfall may happen, resulting in fatalities, injuries, damage to equipment and delays in the operations. At this point, rehabilitation actions need to be taken. The safety consequences and financial implication of ground support failure are enormous, so mines have ground control management plans to mitigate the risk. Monitoring of the ground support is an important part of this process to prevent potential failure (Rahimi et al. 2020).

Ground support control starts with the suppliers; through quality control and laboratory testing they provide geotechnical engineers with reliable material capacity parameters. The specifications from the suppliers alone are not enough because every mine is unique and once installed, the performance of the support in that specific ground condition needs to be qualified thought visual inspection and quantified with in situ testing. These two methodologies (visual inspection and testing) can be utilised for design verification and to identify possible failures so that remediation action can be undertaken in a timely fashion.

\subsection{Ground support installation and capacity}

Routine pull-testing on reinforcement is carried out as common practice in underground mining with recurrence that varies from site to site. An attachment is placed on the rockbolt and axial loading is applied to the reinforcement element. With a force gauge and a ruler, the force-displacement behaviour is recorded during the test as shown in Figure 1a. For practical and safety reasons only, a proof load stipulated by the mine is applied to the bolt to confirm quality of the installation and static performance of the reinforcement. Pull-test can be carried out on all types of reinforcements, however, consideration is required in the case of fully encapsulated bolts. Li (2017), following laboratory tests, explains that in situ pull-testing on fully grouted bolts may not confirm the integrity of the grout over the full length of the bolt, but only examine the anchorage of the critical embodiment length in the borehole near the rock face.

In rockburst prone condition, in situ dynamic testing is becoming popular to directly assess the dynamic capacity of rockbolts. This method consists of a drop test apparatus that utilises a free fall of a mass onto a plate connected to the bolt's head to simulate a seismic event. The force is transferred from the impact plate to the bolt head through a slide rod and a connection claw. The input kinetic energy from the free falling mass is dissipated though deformation and/or displacement of the bolt (Figure 1b). In situ drop testing has been successfully carried out on mechanically anchored bolts (Darlington et al. 2019) and has proven to be an efficient tool in bolt developments and to evaluate dynamic rockbolts in actual conditions as opposed to in the laboratory environment (Roach et al. 2019).

While in situ pull-test and dynamic drop testing prove the load capacity of the ground support (with limitation for fully encapsulated bolts), they inevitably cause damage to the reinforcement. For this reason, non-destructive testing (NDT) has been utilised as an alternative to destructive methodologies. 

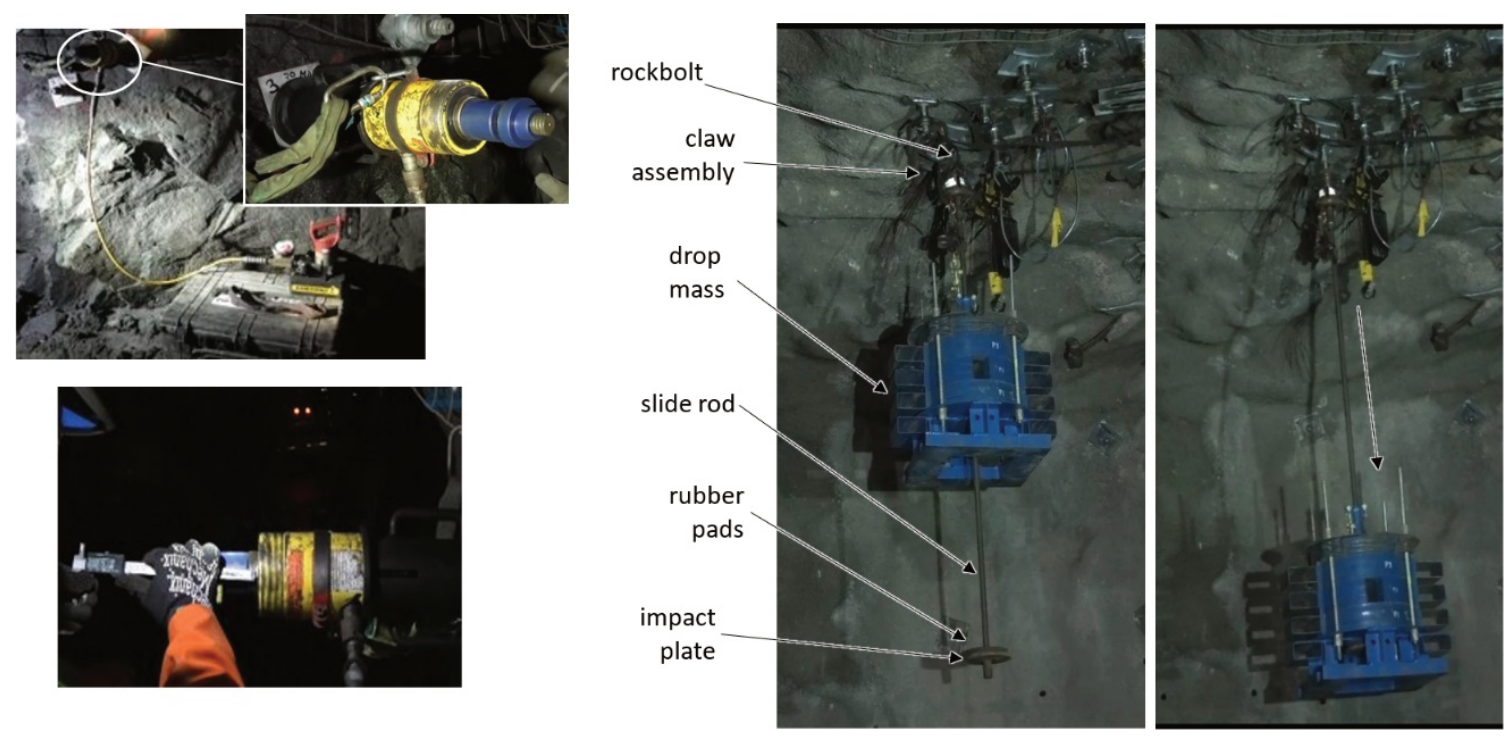

(a)

(b)

Figure 1 Overview of (a) Pull-testing on rockbolt; and (b) In situ drop testing

Acoustic techniques have been developed for testing the installation quality of grouted tendons. The Boltometer in Figure 2a was the first device to be developed in 1983. A sound wave is input in the grouted element and its reflection recorded by a piezometric sensor. If the grout is intact and the steel tendon well coupled with the grout (and with the rock), most of the energy from the sound wave is dissipated in the rock mass. If there are imperfections such as voids or gaps, part of the energy will be reflected and measured by the sensor. In more recent years, Stepinski \& Matsson (2016) developed the rockbolt tester (RBT) (Figure 2b). This device uses ultrasound-guided waves in the form of high-energy, low frequency pulses to detect discontinuities in the grout. The RBT was tested onsite and proved to be able to detect artificially created voids. In Australia, Hartman et al. (2010) proposes an NDT procedure using a simple hammer and a transducer connected to the bolt head called the Mod-Shock (Figure 2c). In the site trials, the transducer was used to pick up the vibration and through frequency analysis and digital filtering, it was possible to detect grout defects.

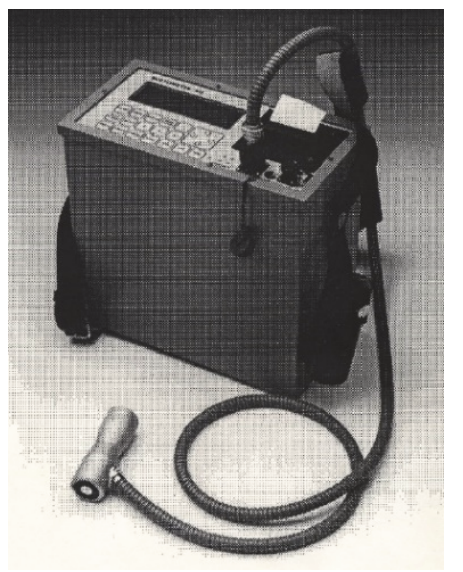

(a)

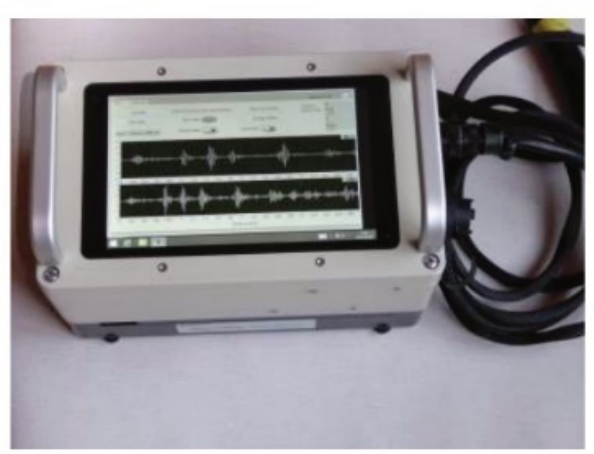

(b)

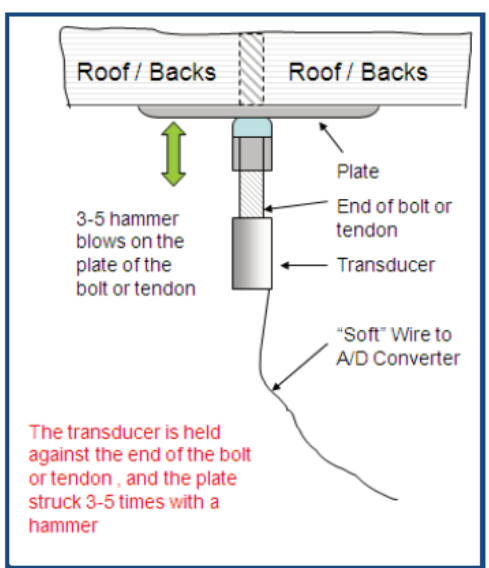

(c)

Figure 2 Overview of (a) Boltometer (Geodynamic 2020); (b) Rockbolt tester (RBT) (Stepinski \& Matsson 2016); and (c) Mod-Shock (Geohart Limited 2018)

In highly stressed or squeezing ground, where rock mass movement occurs over time, the reinforcement will be gradually loaded. In these cases, it is important to keep track of the load experienced by the reinforcement. The most direct method is to use an electronic loadcell. As the name indicates, a loadcell is a 
force transducer that converts the tension experienced by the reinforcement to an electric signal that can be recorded with a reader or a datalogger. Standard practice involves using a hollow sensor between the rock face and rockbolt head. Alternative methods propose to use an instrumented coupler connected to the bar an example is the U-cell as shown in Figure 3 (Mitri 2011).

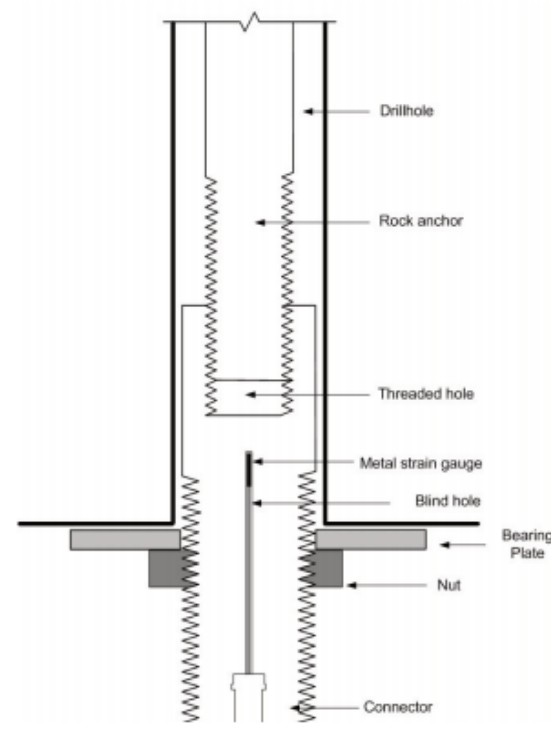

(a)

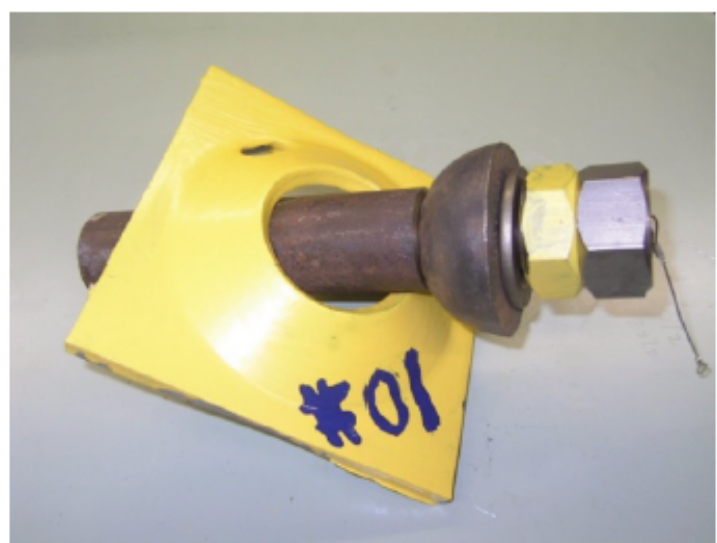

(b)

Figure 3 Overview of U-cell (Mitri 2011): (a) Schematic; and (b) Typical load cell mounted on a rebar

In areas where deeper understanding of the interaction between the rock mass and the reinforcement is needed, fully grouted instrumented reinforcement is deployed. These instruments consist of a reinforcement element integrated with discrete sensors to measure deformation at points along their length. Typically, resistance strain gauges and vibrating wire strain gauges are used. The main limitation with this technology is that only a small area of the reinforcement element can be measured and peak load may be underestimated. For this reason, Hyett \& Spearing (2012) proposed to use longer sensors to cover the entire length of the reinforcement element but also, in this case, due to averaging effects, extreme values can be underestimated. Two configurations were proposed: staggered for enhanced axial load resolution, and stacked to detect bending in the bar (Figure 4). To cope with the limitation of discrete sensing, optical sensors are becoming popular to capture the complete strain profile along the bolt. In recent years, Hoehn et al. (2020), as part of Mining3 project, proposed an improved instrumented rockbolt design. They used a continuous bragg grating, or all grating fibre system that provided strain measurement every $5 \mathrm{~mm}$ along the four shallow slots that were accurately machined on the bar. The instrumented bolt can be connected to a fibre interrogator up to a $1 \mathrm{~km}$ distance for remote and intrinsically safe installation. These instrumented rockbolts are currently being tested in an underground coal mine.

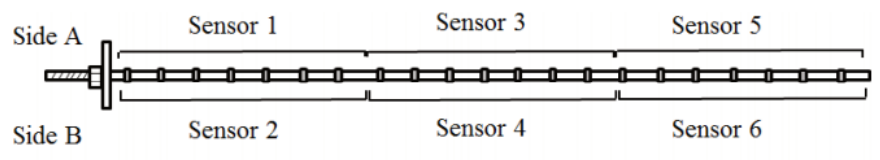

a. Stacked Configuration

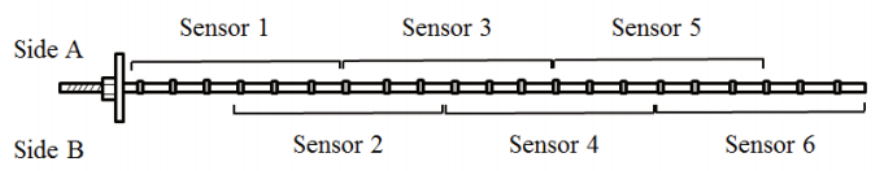

b. Staggered Configuration

Figure 4 Overview of the instrumented rockbolt proposed by Hyett \& Spearing (2012) 
A method to detect overloaded bolts, without using a distributed sensor, was proposed by AMEC and the University of Aberdeen (Neilson et al. 2007). They developed a tool called GRANIT, with a primary function to assess the quality of installation grouting, but it could also be used to detect highly loaded bolts once a number of samples have been tested (exception testing). GRANIT consists of a pneumatic impact device, connected to the head of the anchor, which produces a shock vibration. An accelerometer measures the reinforcement's response and data acquisition records the signal. A trained neural network processes the data and provides a response on the quality of the installation and the load on the bolt. More recently, the approach of measuring the response of the bolt from its head was used by the National Research Council of Canada (Sun et al. 2019). They proposed an ultrasound rockbolt sensor (RBS) for monitoring average load changes and deformation of a rockbolt. The researcher successfully tested the technology with site trials by installing their sensor on the exposed end of several bolts. The signal was directly recorded by a multichannel hub for continuous monitoring or manually read using a portable system. The main disadvantage of GRANIT and RBS is they only provide meaningful, quantitative results if the rockbolt has been characterised at installation. An overview of the two system is presented in Figure 5.

Regarding surface support, regular visual inspection is the main tool used to assess the performance of mesh and shotcrete. It is less common to carry out an instrumented test. A recent attempt was conducted by Whiting (2017), after observing failure of the surface support, by performing pull-testing on different types of mesh to seek improvements. Other instruments found in literature aim to measure the cracks in the shotcrete such as the crackmeter. This sensor can be either a gauge, like a ruler, installed over the crack or an electric sensor connected to a datalogger.

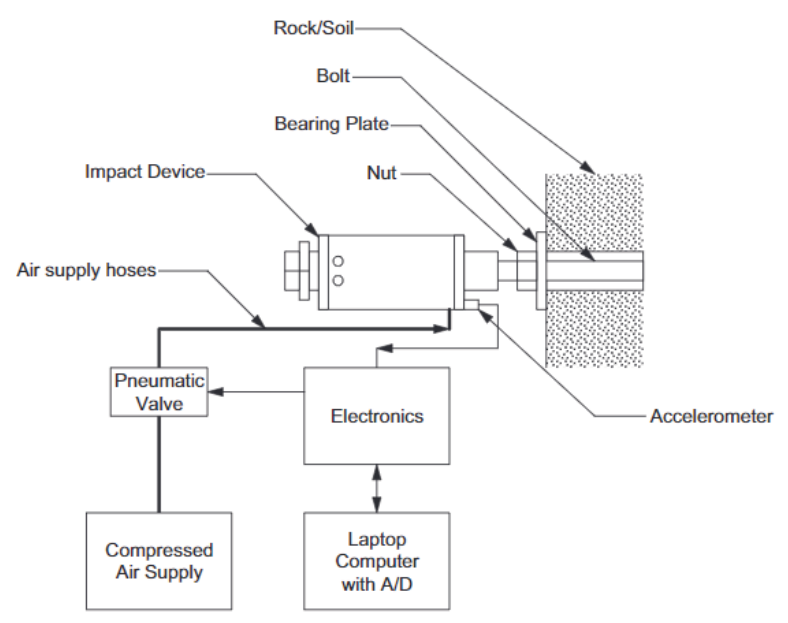

(a)

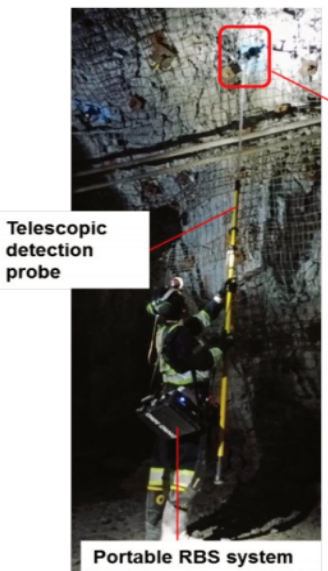

Portable RBS system

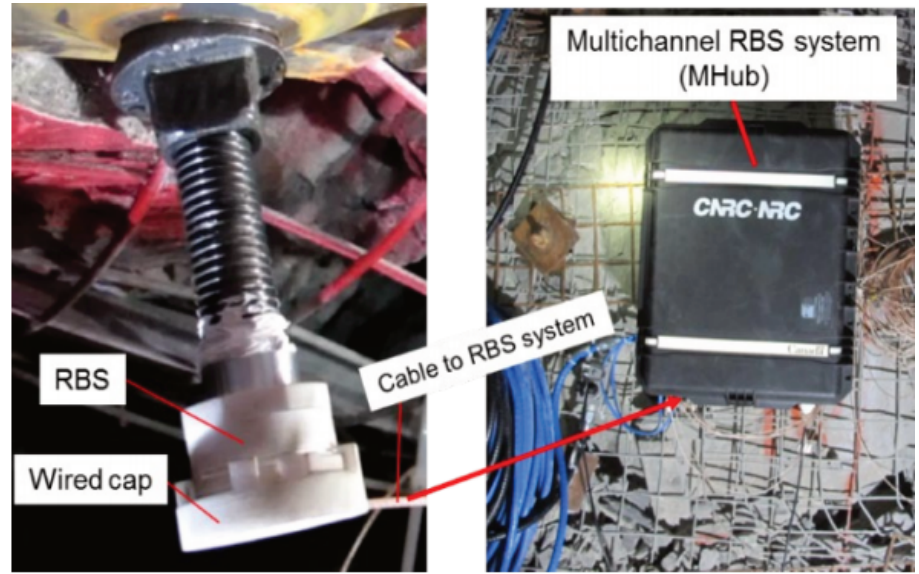

(b)

Figure 5 (a) Schematic of the GRANIT system (Neilson et al. 2007); and (b) Rockbolt sensor (RBS) setup (Sun et al. 2019) 
A different approach to monitor the performance of the ground support is to measure the rock mass and its movement. As a mine advances, the stresses in the rock are redistributed, deformation occurs in the ground and the supports are subjected to load. Measuring and monitoring the movement and load distribution in the rock mass is important to rock mechanic engineers to have a full picture of what is happening in the mine and prevent failures. Tools available in literature to measure the rock mass are presented in the next paragraph.

\section{$3 \quad$ Strata monitoring}

Convergence is a phenomenon related with rock movement, resulting in plastic deformation of a rock mass. With elevated stress, the excavation tends to shrink and collapse, i.e. the walls and/or backs and floors converge over time. This relative movement inside the tunnel can be measured by using a tape or laser range finder. These instruments measure the distance between two fixed points located at the opposite sides of the excavation (i.e. wall to wall measurement or back (roof) to floor) and are usually manually recorded. While this technology offers high accuracy, it is time consuming and only provides discrete measurements. In the past decade, LiDAR technology has become more widely used in the mining industry. A LiDAR scanner allows for a full precise three-dimensional (3D) model reconstruction of an underground excavation. A dataset containing points representing the surfaces of the scanned area is generated by the device and post-processed on a computer. Subsequent scans, carried out in the same location at different times, can be compared and quantitative information of the ground movement can be generated. Magnitude and direction of displacement can be directly read from the 3D model. There are two types of LiDAR devices: stationary scanners and mobile scanners. Stationary (or fixed) scanners are mounted on the wall and monitor the same area over time with sub-millimetre accuracy. Mobile scanners are less accurate but they have the advantage of covering larger areas in a short time. They are usually carried around by hand (Andrews et al. 2019), connected to a vehicle (Lynch et al. 2017) or even attached to drones (Jones et al. 2019). A typical output from a LiDAR scanner is shown in Figure 6.
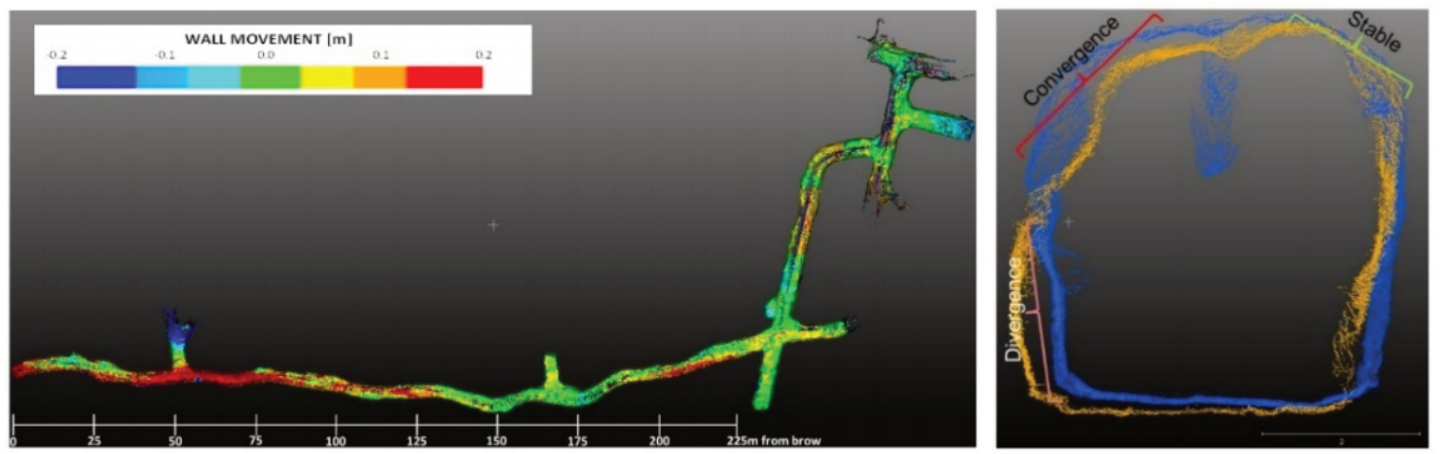

Figure 6 Example of convergence detection using dataset from mobile LiDAR scanner (Jones \& Beck 2017)

An alternative to measuring distances internally in a tunnel is to use devices or instruments placed inside boreholes in the rock mass. The most common examples are telltales and extensometers. Telltales are an inexpensive and easily installed safety monitoring device. Telltales are typically installed in vertical boreholes in the back, with the anchor in stable rock and the tail protruding from the rock face. They offer a visual indication of the movement occurring in the surrounding rock mass. The installation of these devices involves drilling a hole (typically up to $10 \mathrm{~m}$ long) and inserting an anchor using an ad hoc installation rod. There are different models that vary in the number of anchors and the shape of the gauge indicator. Telltales are widely used because they offer clear (typically coloured) visual indication of movement that can be easily interpreted by mining personal. Keeping track of the measurement from these devices is an enormous workload because of the large number of units deployed. For this reason, practitioners are proposing digital telltales that allow remote monitoring (Conover \& Bigby 2010). Extensometers are electronic devices installed in boreholes, and unlike telltales, are usually fixed solidly in place with grout to improve measurement accuracy. They feature one or more sensors along their length and they can be manually read 
with a handheld device, connected to a datalogger, or to a Wi-Fi network for continuous real-time monitoring. Examples of the two devices are shown in Figure $7 a$ and $b$ respectively.

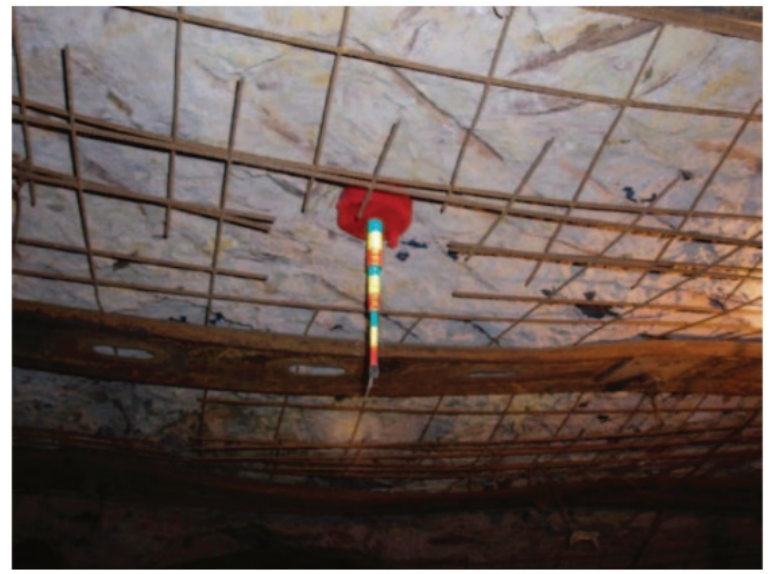

(a)

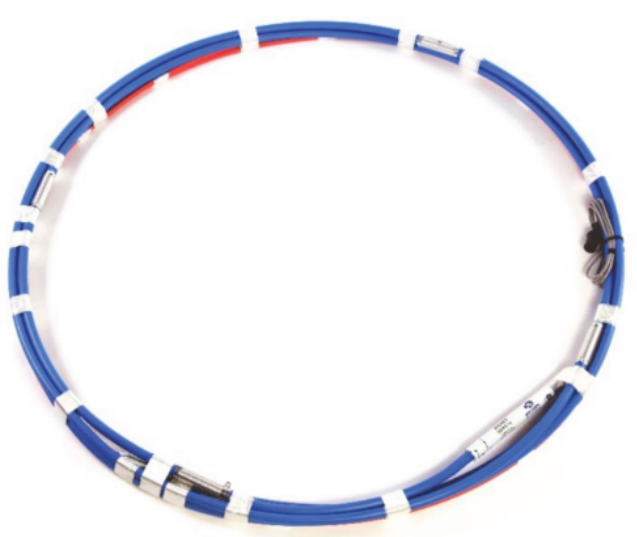

(b)

Figure 7 (a) Typical telltale installed in the back (Conover \& Bigby 2010); (b) Example of a multiprobe extensometer (Mine Design Technologies Australia 2020)

Not only can movement be measured inside boreholes, a hydraulic pressure cell (Figure 8a) can be used to directly measure the stress in the rock mass. Forbes et al. (2019) describes their use among other instruments in a monitoring campaign of hard rock pillars. In their study, they used a flat jack type instrument grouted in boreholes. This device only measures stress in the direction perpendicular to the flat jack (i.e. multiple sensors orientated in different directions are needed to resolve the full stress tensor). A different type of cell is the Hi-Cell developed by CSIRO (Figure 8b). This sensor is equipped with strain gauges that allows for 3D stress measurement. The Hi-Cell is installed in a borehole with an adhesive and can then be left in situ for long-term stress change measurement or can be over-cored. With this latter process, the elastic relief stresses generated by the unloading are measured.

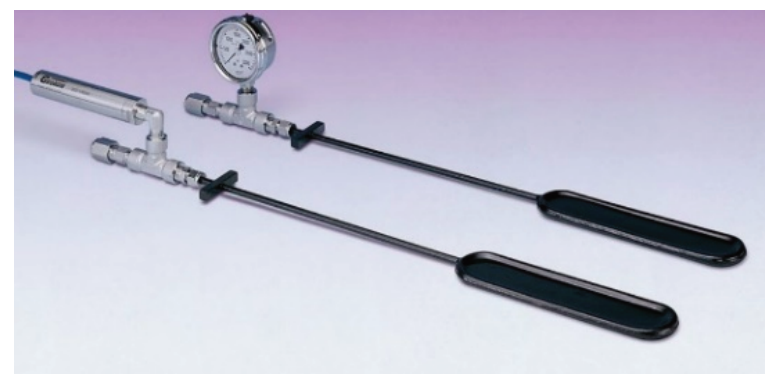

(a)

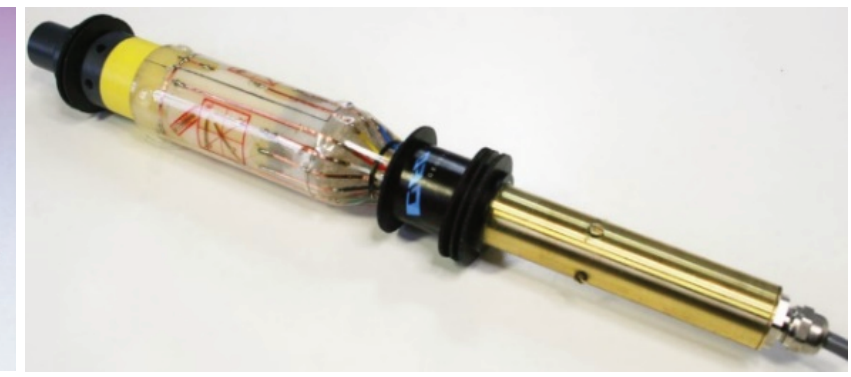

(b)

Figure 8 (a) Flat jack pressure cell (Geokon 2019); (b) Hi-Cell (ESS Earth Sciences 2020)

As underground mining reaches deeper areas, higher stresses may lead to seismic events or rockburst. These violent occurrences raise serious concern over the stability and safety of the mine and to mitigate this risk, engineers rely on microseismic monitoring. This system gives information about the location, frequency, and magnitude of seismic events and source parameters. With this information, engineers can visualise how mine operations are influencing rock mass behaviour, active seismic areas, and monitor the condition over time. Seismic data can be used in re-entry procedures following large events, and through back-analysis can be used to improve mine design sequences and to assess the performance and efficiency of the ground support (Queen's University 2014). Data is collected by sensors and displayed on 3D visualisation software. The monitoring system consists of a network of geophones and/or accelerometers installed in boreholes that can sense the vibrations generated by rock fracturing. Number of sensors, typology, sensitivity and location needs to be carefully designed to have the best results and reliable measurements (Hallo 2012). 


\section{$4 \quad$ Technology trends}

Ground support and strata monitoring technologies are evolving quickly as part of the digital transformation that is embracing the mining industry. In the mines, technological changes are driven by the need to reduce operational costs while enhancing productivity and providing safety in the work environment (Ramdoo 2019). These changes are enabled by technological advances, their decreasing cost and the accessibility of network communication, even in remote underground locations. As a result, the mining industry is experiencing high demand for automating and optimising all aspect of their operations. Leading technology suppliers, such as Sandvik, are investing in the development of new equipment and integrated digital systems. These systems allow for autonomous tele-remote operation (i.e. Automine ${ }^{\circledR}$ ) along with real-time visualisation software for analysing and optimising mining production and processes (i.e. Optimine ${ }^{\circledR}$ ). An example of the potential of automation is shown in Figure 9 with an autonomous loader driving though a glass labyrinth. Additional information on mining automation products can be found on Sandvik Rock Technology website (https://www.rocktechnology.sandvik/en/products/automation/).
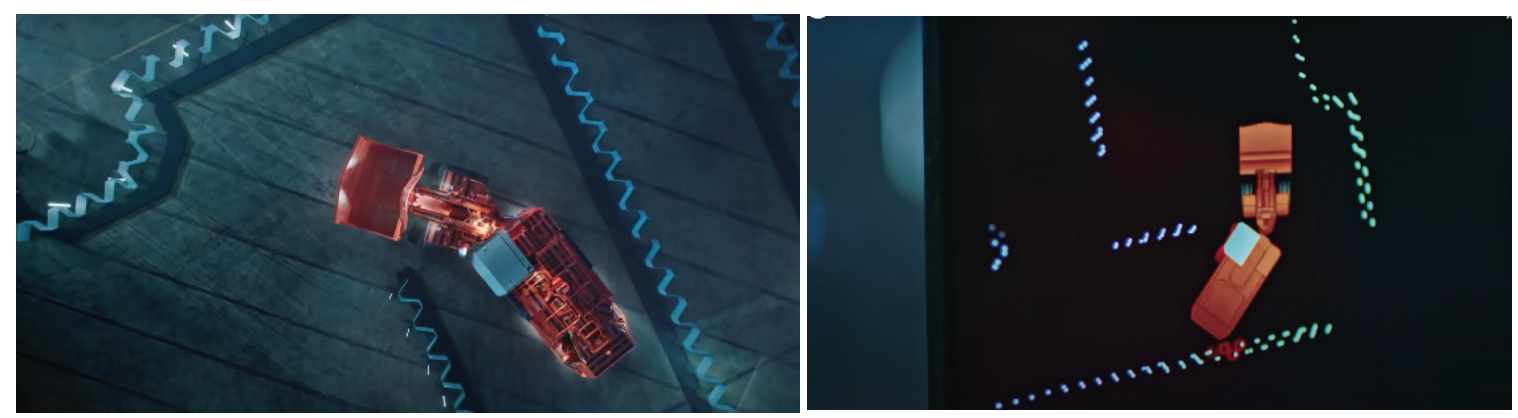

Figure 9 A $38 \mathrm{t}$ automated loader driving autonomously through a glass labyrinth (Sandvik 2018)

Regarding monitoring applications, evolving sensor technology is the key enabler of digital transformation. A sensor is a device that detects and/or measures a physical event and converts it into an electric signal that can be interpreted by a computer. With advances in network communications, sensors can be easily connected to the internet to provide users with real-time data. Such a concept is already used in many mines for real-time seismic monitoring and environment sensing for toxic, flammable gases, dust, humidity and temperature.

When inter-connected sensors are embedded in physical devices and everyday objects, we can talk about the Internet of Things (IoT). An example of an loT application in underground mining is the Newtrax system (Campeau \& Dubois 2019). This system collects data from a large variety of sources: location of personnel can be tracked by tracking-enabled cap lamps; environmental data from geotechnical and ventilation instruments; vehicle data from sensors installed on equipment and machines. This latter data was utilised in combination with machine learning techniques for maintenance prediction of mobile equipment, showing potential cost saving by predicting equipment failure before it happens.

Regarding ground support, an example of including sensors with enhanced connectivity in rockbolts can be found in the Smart Rockbolt developed by researchers from Luleå University of Technology (Pereira 2016). This device has sensors to measure tilt, deformation and vibration in order to detect failure or dangerous situations. An alert can be transmitted through the network for real-time assessment eliminating the need of going underground for data collection. This technology is in its initial stages and not yet commercially available. An overview of the loT bolt attachment device is presented in Figure 10a.

A different method of collecting data without (or with minimised) human interaction, utilises autonomous and semi-autonomous drones integrated with LiDAR scanners. An example of such a device is the Hovermap developed by Emesent (Jones et al. 2019) in Figure 10b. Hovermap is an attachment (detachable payload) mounted on a drone which includes two LiDAR scanners, an inertial measurement unit and a processor, which allows for position recognition and sensing even in an underground environment where GPS is not available. The Hovermap has different levels of autonomy and through collision avoidance, enables flight beyond the line of sight with minimal input from the pilot. The device has been tested in different case studies including 
deformation monitoring and ground support analysis and, according to the researchers, would be able to detect changes of approximately $10 \mathrm{~mm}$ and convergence trends. Research in this area is very active and aimed to provide a fully autonomous system.

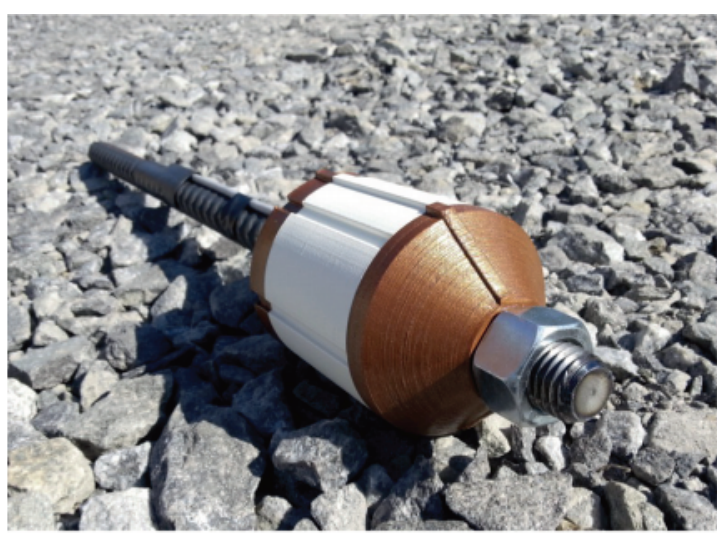

(a)

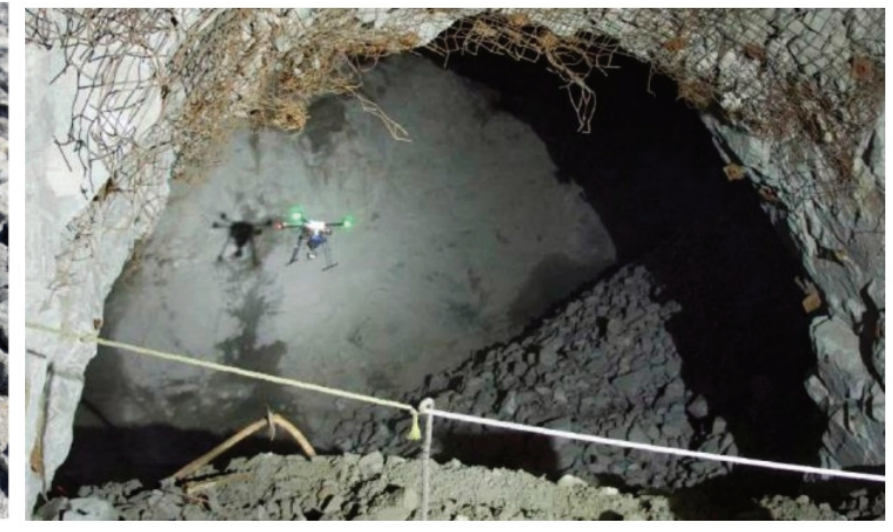

(b)

Figure 10 (a) Smart Rockbolt prototype (Pereira 2016); (b) Hovermap flying through an open drawpoint into a large stope (Jones et al. 2019)

The use of monitoring instrumentation in ground support design has been well documented in literature. The observational approach proposes a cyclic methodology (design-implementation-monitor-redesign) that continuously checks on performance of the support design as a way of dealing with geomechanics uncertainty (Dunn 2013). As more data becomes continuously available in near real-time, new methodology for risk assessment and ground support optimisation can be explored, such as the framework proposed by Mishra (Mishra et al. 2016). The researcher concluded that with periodic and real-time measurement, it is possible to improve risk management processes. A better understanding of the interaction between rock stresses and underground excavation performance can help to increase the design confidence level.

The next logical step forward in the use of monitoring data is in the domain of advanced analytics, machine learning and artificial intelligence. These terms include technology that uses large data sets, artificial neural networks and algorithms, is able to perform analysis, detect patterns in the data and, eventually, learn autonomously how to make decisions. As previously mentioned, this technology is already used in mining, e.g. for machinery maintenance. In rock mechanics problems, its application presents challenges (McGaughey 2019). The data for analysis is often not available at the location where the prediction is needed and many of the factors affecting the prediction are inferred from models that are themselves created from sparse measurement. In his study, McGaughey argues that the application of artificial intelligence (Al) in rock mechanics can be aimed at finding patterns and correlations among multiple data sets and creating statistical models to produce a set of rules that can be used to predict future behaviours. The researcher supported the thesis that through machine learning and $\mathrm{Al}$, success can, and has been, achieved in mining geomechanics. He concluded presenting a data management system for the application of Al for mining problems (such as rockburst, rockfall or slope failure).

\section{$5 \quad$ Discussion and conclusion}

An overview of devices and methodologies for monitoring the performance of ground support and rock mass behaviour was given in Sections 2 and 3, respectively. Ground support elements should ensure a safe work environment; their performance and the rock mass behaviour should be monitored over time. Such monitoring should start from installation and cover the entire operational life of the excavation. Being located inside the rock, reinforcement suffers from a lack of the ability for direct observation, so that most of the problems-like poor grouting, shearing and corrosion-cannot be directly assessed visually. Destructive testing can be utilised to confirm the load capacity of the reinforcement, however, to determine the long-term performance, non-destructive methods are more effective. In particular, how much of the 
load/deformation capacity has been consumed in the reinforcement is a topic that researchers and industry are investigating and willing to address (Australian Centre for Geomechanics 2020). Answering this question will improve safety and integrity of the working environment and reduce costs of remediation actions due to ground support failure.

Ground support elements are bound together with the rock mass and are directly influenced by movement in the strata. Consequently, it is essential to monitor the ground support, strata conditions and the interaction between them. Stresses, movement and seismic vibrations can be measured with instruments embedded in the rock mass while convergence measurement can be carried out inside the tunnel with LiDAR scanners. This latter technology is receiving positive feedback from the industry for the ease of use and value of captured data. However, at the same time, scans can be time-consuming to acquire and only carried out some time after the installation of ground supports, such that early loading history cannot be extrapolated.

New technologies are becoming available as the digital transformation is reaching the mining industry. Value in investing in these new technologies can be found in cost-saving by optimising and automating operations. In the monitoring sector, new technologies are successfully being applied for tracking of personnel and equipment and for failure prediction of machinery. Regarding ground support and strata monitoring, two technologies are promising for the future, largely deployed network of sensors (IoT and real-time seismic monitoring) and autonomous drone for LiDAR scanners. In particular the network of sensors allows for real-time and continuous monitoring. This can be used in real-time risk assessment, ground support design optimisation and, eventually, for advanced analytics and Al.

Concern has been raised on how ready the mining sector is for the digital transformation (Gao et al. 2019). The researcher performed interviews with companies that operate in the mining sector (mining firms and suppliers) between 2016 and 2019. The findings can be summarised in four main themes: lack of capability to change; difficulties to determinate goals to achieve; technological problems; and external constraints related to operating environment, health and safety, legislation, politics and social responsibility.

Nevertheless, an automated and more sustainable mining environment is a must for the future with enormous potential benefits in cost saving despite the initial upfront investment. An example is the Syama mine in Mali that is undertaking a digital transformation supported by Sandvik.

"The combination of mine automation, improved recoveries, and lower cost power has the potential to increase site production to 300,000 ounces of gold per annum and reduce Lifeof-Mine All-In Sustaining Costs to below US\$750 per ounce." (Syama Gold Mine Factsheet)

In the Syama story, and in the author's opinion, one key enabler to take full advantage of the new technologies is bringing network communication underground (i.e. fibre optic, Wi-Fi, LTE or 4G/5G). A good network is essential to provide the necessary back bone for data exchange between underground personnel, equipment, instrumentation and the control room on the surface and/or other remote locations. In a monitoring application, this will enable the mine operator to have real-time, remote and wireless sensing that allows for a timely response to any unwanted occurrences happening in the excavation.

For the digitalisation process to provide real value to the mine, suppliers and researchers should invest in research and development and the customer (i.e. rock mechanics and geotechnical engineers) should provide feedback on the requirements of the industry. A collaboration between these two entities is essential to produce valuable products that solve real problems. This is valid also for ground support and strata monitoring technology. In this context, this paper wants to invite the industry for a more open dialogue on the topic and suggest the interested parties subscribe to relevant publications and attend conferences and events to gain knowledge of the up-coming technology trends.

\section{Acknowledgement}

During the process of producing this paper, the work was the joint effort of the authors. 


\section{References}

Andrews, PG, Rwodzi, L, Ekkerd, J \& Ratshitaka, N 2019, 'Advanced techniques for the monitoring of pillar and excavation behaviour at a deep level massive mine', in W Joughin (ed.), Proceedings of the Ninth International Conference on Deep and High Stress Mining, The Southern African Institute of Mining and Metallurgy, Johannesburg, pp. 133-148, https://doi.org/10.36487/ ACG_rep/1952_11_Andrews

Australian Centre for Geomechanics 2020, GSSO Phase 2, viewed 27 July 2020, https://gsso.com.au/phase-2/

Bačić, M, Gavin, K \& Kovačević, MS 2019, 'Trends in non-destructive testing of rock bolts', Građevinar, vol. 71, issue 10, pp. 823-831, https://doi.org/10.14256/JCE.2727.2019

Campeau, LP \& Dubois, M 2019, 'Artificial intelligence using real-time data', in C Mueller, W Assibey-Bonsu, E Baafi, C Dauber, C Doran, M Jerzy Jaszczuk \& O Nagovitsyn (eds), Proceedings of the 39th International Symposium 'Application of Computers and Operations Research in the Mineral Industry', CRC Press, Cleveland, pp. 557-562.

Conover, D \& Bigby, D 2010, 'Recent experience using telltale roof monitoring systems', Proceedings of the 29th International Conference on Ground Control in Mining, West Virginia University, Morgantown, pp. 243-247.

Darlington, B, Rataj, M \& Roach, W 2019, 'A new method to evaluate dynamic bolts and the development of a new dynamic rockbolt', in W Joughin (ed.), Proceedings of the Ninth International Conference on Deep and High Stress Mining, The Southern African Institute of Mining and Metallurgy, Johannesburg, pp. 205-216, https://doi.org/10.36487/ACG_rep/1952_16_Darlington

Dawn, T 2019, 'Technologies of ground support monitoring in block caving operations', in J Hadjigeorgiou \& M Hudyma (eds), Proceedings of the Ninth International Symposium on Ground Support in Mining and Underground Construction, Australian Centre for Geomechanics, Perth, pp. 109-122, https://doi.org/10.36487/ACG_rep/1925_06_Dawn

Dunn, MJ 2013, 'Uncertainty in ground support design and implementation in underground mining', in Y Potvin \& B Brady (eds), Proceedings of the Seventh International Symposium on Ground Support in Mining and Underground Construction, Australian Centre for Geomechanics, Perth, pp. 345-358, https://doi.org/10.36487/ACG_rep/1304_22_Dunn

ESS Earth Sciences 2020, 3D Stress CSIRO Analogue HI Cell, viewed 27 July 2020, http://www.essearth.com/product/3d-stress-cellcsiro-hollow-inclusion-hi-cell/

Forbes, B, Vlachopoulos, N, Diederichs, MS, Hyett, AJ \& Punkkinen, A 2019, 'An in situ monitoring campaign of a hard rock pillar at great depth within a Canadian mine', Journal of Rock Mechanics and Geotechnical Engineering, vol. 12, pp. 427-448.

Gao, S, Hakanen, E, Töytäri, P \& Rajala, R 2019, 'Digital transformation in asset-intensive businesses: Lessons learned from the metals and mining industry', Proceedings of the 52nd Hawaii International Conference on System Sciences, https://doi.org/10.24251/HICSS.2019.593

Geodynamik 2020, Boltometer 011 , viewed 27 July 2020, http://www.geodynamik.com/languages/pdf/mbo.pdf

Geokon 2019, Model 3200 Borehole Pressure Cell, instruction manual, https://www.geokon.com/content/ manuals/3200_Hydraulic_Borehole_Pressure_Cell.pdf

Geohart Limited 2018, Capability Statement 2018, viewed 27 July 2020, http://www.geohart.com.au/wpcontent/uploads/2014/02/Geohart-Non_Destructive-Testing_2018_v1.pdf

Hallo, M 2012, 'Microseismic surface monitoring network design - sensitivity and accuracy', Proceedings of the 74th EAGE Conference and Exhibition 2012, European Association of Geoscientists \& Engineers, Houten.

Hartman, W, Harvey F, Lecinq, B Higgs, J \& Tongue, D 2010 'Managing geotechnical risk through non-destructive rock reinforcement testing trialled at the George Fisher Mine, Mt. Isa.', Proceedings of the Second Australasian Ground Control in Mining Conference, The Australasian Institute of Mining and Metallurgy, Carlton.

Hoehn, K, Spearing, AJS, Jessu, KV, Singh, P \& Pinazzi, PC 2020, 'The design of improved optical fibre instrumented rockbolts', Geotechnical and Geological Engineering, vol. 38, pp. 4349-4359, https://doi.org/10.1007/s10706-020-01246-0

Hyett, A \& Spearing, AJS 2012, 'New Technology for Measuring the In Situ Performance of Rock Bolts', Proceedings of the 46th US Rock Mechanics/Geomechanics Symposium, American Rock Mechanics Association, Alexandria, https://www.yieldpoint.com/uploads/pdf/ARMA_2012_Chicago.pdf

Jones, E \& Beck, D 2017, 'The use of 3D laser scanning for deformation monitoring in underground mines', Proceedings of the 13th AusIMM Underground Operators' Conference 2017, The Australasian Institute of Mining and Metallurgy, Carlton.

Jones, E, Sofonia, J, Canales, C, Hrabar, S \& Kendoul, F 2019, 'Advances and applications for automated drones in underground mining operations', in W Joughin (ed.), Proceedings of the Ninth International Conference on Deep and High Stress Mining, The Southern African Institute of Mining and Metallurgy, Johannesburg, pp. 323-334, https://doi.org/10.36487/ACG_rep/1952_24_Jones

Kanda, MJ \& Stacey, TR 2019, 'Review of the practical effectiveness of thin spray-on liners based on information from suppliers and observations from the mining industry', in J Wesseloo (ed.), Proceedings of the First International Conference on Mining Geomechanical Risk, Australian Centre for Geomechanics, Perth, pp. 443-458, https://doi.org/10.36487/ ACG_rep/1905_27_Kanda

Li, CC 2017, Rockbolting: Principles and Applications, Butterworth-Heinemann, Oxford.

Lynch, BK, Marr, J, Marshall, J A \& Greenspan, M 2017, 'Mobile LiDAR-based convergence detection in underground tunnel environments', https://qspace.library.queensu.ca/handle/1974/15638

McGaughey, J 2019, 'Artificial intelligence and big data analytics in mining geomechanics', in W Joughin (ed.), Proceedings of the Ninth International Conference on Deep and High Stress Mining, The Southern African Institute of Mining and Metallurgy, Johannesburg, pp. 45-54, https://doi.org/10.36487/ACG_rep/1952_04_McGaughey

Mine Design Technologies Australia 2020, SMART MPBX (Multi-Point Borehole eXtensometer), https://au.mdt.ca/products/ instrumentation/smart-mpbx/\#) 
Mishra, RK, Ritala, F, Janiszewski, M, Uotinen, L \& Siren, T 2016, 'Real-Time Risk Assessment and Ground Support Optimisation in Underground Mines', in E Nordlund, TH Jones \& A Eitzenberger (eds.), Proceedings of the Eighth International Symposium on Ground Support in Mining and Underground Construction, Luleå University of Technology, Luleå.

Mitri, H 2011, 'Evaluation of Rock Support Performance through Instrumentation and Monitoring of Bolt Axial Load', Proceedings of the 11th Underground Coal Operators' Conference, University of Wollongong, Wollongong, and The Australasian Institute of Mining and Metallurgy, Carlton, pp. 136-140.

Morissette, P \& Hadjigeorgiou, J 2017, 'The development of a ground support design strategy for deep mines subjected to dynamicloading conditions', in J Wesseloo (ed.), Proceedings of the Eighth International Conference on Deep and High Stress Mining, Australian Centre for Geomechanics, Perth, pp.651-665, https://doi.org/10.36487/ACG_rep/1704_44_Morissette

Neilson, DR, Ivanović, A, Starkey, AJ \& Rodger, AA 2007, 'Design and dynamic analysis of a pneumatic impulse generating device for the non-destructive testing of ground anchorages', Mechanical Systems and Signal Processing, vol. 21, pp. 2523-2545, https://doi.org/10.1016/j.ymssp.2006.11.011

Pereira, PP 2016, Efficient loT Framework for Industrial Applications, PhD thesis, Luleå University of Technology, Luleå.

Potvin, Y \& Hadjigeorgiou, J 2020, Ground Support for underground mines, Australian Centre for Geomechanics, Perth.

Queen's University MineWiki 2014, Mining induced seismicity, viewed 27 July 2020, https://minewiki.engineering.queensu.ca/ mediawiki/index.php/Mining_induced_seismicity

Rahimi, B, Sharifzadeh, M \& Fen, XT 2020, 'Ground behaviour analysis, support system design and construction strategies in deep hard rock mining - Justified in Western Australian's mines', Journal of Rock Mechanics and Geotechnical Engineering, vol. 12, pp. 1-20.

Ramdoo, I 2019, Technology Impacts Review, viewed 27 July 2020, https://www.iisd.org/sites/default/files/publications/new-technew-deal-technology.pdf

Roach, W, Rataj, M \& Darlington, B 2019, 'Development of a new Sandvik 'little brother' dynamic rockbolt and the in situ dynamic evaluation of bolts', in J Hadjigeorgiou \& M Hudyma (eds), Proceedings of the Ninth International Symposium on Ground Support in Mining and Underground Construction, Australian Centre for Geomechanics, Perth, pp. 201-212, https://doi.org/10.36487/ACG_rep/1925_12_Roach

Sandvik 2018, Sandvik Let's Create: The Glass Labyrinth and the Giant Loader, YouTube, https://www.youtube.com/ watch?v=7B2s6C1IAoQ

Song, G, Li, W, Wang, B, Chun, S \& Ho, M 2017, 'A Review of Rock Bolt Monitoring Using Smart Sensors', Sensors, vol. 17, issue 4, https://doi.org/10.3390/s17040776

Stepinski, T \& Matsson, KJ 2016, 'Rock Bolt Inspection by Means of RBT Instrument', Proceedings of the 19th World Conference on Non-Destructive Testing, https://www.ndt.net/article/wcndt2016/papers/we4a5.pdf

Sun, Z, Wu, KT, Kruger, SE, Levesque, D, Gagnon, D, Quenneville, Y...\& Royer, R 2019, 'A new paradigm in ground support monitoring through ultrasonic monitoring of clusters of rockbolts', in J Hadjigeorgiou \& M Hudyma (eds), Proceedings of the Ninth International Symposium on Ground Support in Mining and Underground Construction, Australian Centre for Geomechanics, Perth, pp. 75-84, https://doi.org/10.36487/ACG_rep/1925_03_Sun

Whiting, RK 2017, 'In situ static performance assessment of mine mesh', in J Wesseloo (ed.), Proceedings of the Eighth International Conference on Deep and High Stress Mining, Australian Centre for Geomechanics, Perth, pp. 747-762, https://doi.org/10.36487/ACG_rep/1704_51_Whiting 